\title{
Duloxetine Attenuated Morphine Withdrawal Syndrome in the Rat
}

\author{
Authors \\ M. Charkhpour ${ }^{1}$, R. M. Jafari ${ }^{1}$, H. Ghavimi ${ }^{2,3}$, S. Ghanbarzadeh ${ }^{3,4}$, A. Parvizpur ${ }^{1,5}$ \\ Affiliations \\ Affiliation addresses are listed at the end of the article
}

Key words
duloxetine
morphine
withdrawal syndrome
rat
serotonin

received 17.09 .2013

accepted 24.10.2013

\section{Bibliography}

DOI http://dx.doi.org/

10.1055/s-0033-1358728

Published online:

November 21, 2013

Drug Res 2014;

64: 393-398

(c) Georg Thieme Verlag KG

Stuttgart · New York

ISSN 2194-9379

Correspondence

\section{A. Parvizpur}

Assistant Professor of

Pharmacology

Department of Pharmacology

and Toxicology

Faculty of Pharmacy

Tabriz University of Medical

Sciences

Daneshgah Ave.

P.O.Box 51664-14776

Tabriz

Iran

Tel.: + 98/411/3341315

Fax: + 98/411/3344 798

AR.Parvizpur@yahoo.com

A.parvizpur@excite.com

\section{Abstract}

$\nabla$

Background: Long term exposure to morphine can induce dependence. The exact mechanisms of dependence are not yet fully understood. Many studies have been conducted to find new drugs that can prevent dependence. This study examined the effects of the chronic administration of duloxetine on the morphine withdrawal syndrome in rats.

Methods: To this end, male Wistar rats (170$220 \mathrm{~g}$ ) were randomly divided into 5 groups including one saline treated group (non-dependent group) and 4 morphine dependent groups. The experimental groups received additive doses of morphine for 9 days in order to induce dependence according to the following protocol: day $1: 5 \mathrm{mg} / \mathrm{kg} / 12 \mathrm{~h}$, days 2 and 3: $10 \mathrm{mg} / \mathrm{kg} / 12 \mathrm{~h}$, days 4, 5: $15 \mathrm{mg} / \mathrm{kg} / 12 \mathrm{~h}$, days 6 and 7: $20 \mathrm{mg} /$

\section{Introduction}

Morphine and other opioids are regularly used to control severe pain in patients with various clinical conditions such as cancer, renal calculus, heart attack, and traumatic injuries. Development of tolerance to the analgesic effect and the physical dependence are two major problems related to the chronic use of morphine and other opioids that obstruct their therapeutics utilizations. Various behavioral symptoms characterize the opioid dependence when the opiate consumption is ceased or the opioid antagonists are administered [1,2]. Because of these problems, many scientists are challenged and numerous studies have been conducted on the experimental animals to identify effective drug therapy for this difficulty. Acute opiate exposure inhibits the adenosine 3',5'-monophosphate (cAMP) pathway in neurons, whereas in the prolonged treatment compensatory up-regulation of the cAMP pathway is observed [3]. In this regard, the up- $\mathrm{kg} / 12 \mathrm{~h}$ and days 8 and 9: $25 \mathrm{mg} / \mathrm{kg} / 12 \mathrm{~h}$. On the ninth day, the morning dose of morphine was only injected. It is worth noting that $30 \mathrm{~min}$ before the morning dose of morphine, duloxetine $(10,20$, and $40 \mathrm{mg} / \mathrm{kg})$ was injected intraperitoneally. In addition, $2 \mathrm{~h}$ after the last injection of morphine, the morphine withdrawal was precipitated by naloxone. The withdrawal signs were recorded for $30 \mathrm{~min}$; these signs included jumping, rearing, genital grooming, abdominal writhing, wet dog shaking, and teeth grinding.

Results: The results of the study revealed that the chronic administration of duloxetine decreased all the withdrawal signs. Besides, it attenuated the total withdrawal scores significantly.

Conclusion: Results indicate that the regulatory effects on serotonergic and noradrenergic parameters might be associated with the amelioration of the withdrawal symptoms.

regulation of the CAMP pathway is the best established molecular adaption to dependence and addiction [4]. Upon the removal of the opiate agonists, the up-regulation of the cAMP pathway also opposes the acute inhibition of this pathway and thereby represents a form of the opioid dependence. Hence, clonidine ( $\alpha_{2}$ adrenoceptors agonist) and beta receptor blockers such as propranolol are used for attenuating the withdrawal signs in addicts through their inhibitory effect on adenylyl cyclases activity and the suppression effect on the cAMP production [5]. Besides, the morphine treatment not only changes the signaling pathways but also it modulates auto- and hetero-receptors. A recent study has demonstrated that 5 -HT $1_{\mathrm{A}}$ auto-receptors and $\alpha_{2}$-adrenoceptors, which regulate serotonin (5-HT) and noradrenaline (NA) synthesis in the central nervous system, respectively, are supersensitive during the chronic morphine treatment and the opiate withdrawal [6]. Hence, the supersensitivity of these regulatory receptors inhibits the 5-HT 
synthesis and increases the NA synthesis in the brain during the prolonged treatment of opiate and its withdrawal [6]. Moreover, the Locus Coeruleus (LC), a bilateral nucleus in the brain stem, is the major noradrenergic nucleus that regulates the attention states and the activity of the autonomic nervous system in the brain. The LC is also implicated in the somatic opiate withdrawal signs [7]. In this regard, pharmacological and behavioral studies have indicated that the hyperactivity of the LC plays an important role in the precipitation of the physical signs of the opiate withdrawal $[8,9]$. This finding is in accordance with the results of other study that demonstrated that lesion to the LC reduces the somatic signs of the opioid withdrawal [10]. The LC also innervates heavily through serotonergic fibers and terminals [11]. Furthermore, from an anatomical perspective, the LC contains high levels of both 5-HT reuptake and its binding sites. This dense innervation through the serotonergic fibers emphasize that the serotonin plays an important role in controlling the noradrenergic LC neurons discharge. It is worth nothing that the serotonergic neurons denervation and the 5-HT synthesis inhibition are two conditions that increase the NA synthesis in the LC. Moreover, microdialysis studies on rats have shown that following administration of the $5-\mathrm{HT}_{2}$ receptor agonists reduces the spontaneous noradrenergic activity of the LC [12]. In this respect, Done and Sharp used the microdialysis technique and determined the NA concentration in the rat hippocampus. They reported the inhibitory influence of the 5-HT agonists on the NA synthesis in this nucleus [13]. In addition, the latter study suggested that the $5-\mathrm{HT}_{2}$ receptors mediate the 5-HT inhibitory effect on the NA synthesis [13]. Duloxetine is also a 5-HT and NA reuptake inhibitor [14] that inhibits the 5-HT reuptake 5-fold greater than the NA [15]. Besides, it inhibits the reuptake of dopamine weakly, and is also inactive as a ligand to opioid, dopaminergic, histaminergic, and beta and alpha-adrenergic as well as serotonergic and muscarinic receptors [16]. It is worth noting that due to the unimportant affinity of duloxetine for binding up the ion channels like glycine and $\mathrm{GABA}_{\mathrm{A}}$, and transporters such as choline and gamma-aminobutyric acid transporters [17], it also has a mild side effects and is used for the treatment of major depressive disorder (especially in patients with urinary incontinence) [18], generalized anxiety disorder [17], pain [19], and fibromyalgia as well [20]. Fuller, et. al. further reported that duloxetine antagonize the depletion of the brain's 5-HT through $p$-chloroamphetamine and the depletion of the heart's NA by means of 6-hydroxydopamine in mice [21]. Moreover, Rueter, et. al revealed that the chronic administration of duloxetine in the rats produced the regulatory effects on both the serotonergic and the noradrenergic parameters through the desensitization of the $5-\mathrm{HT}_{1 \mathrm{~A}}$ auto-receptors and the $\alpha_{2^{-}}$ adrenergic hetroceptors on nervous terminals [22]. The purpose of the present study is to investigate the effects of various doses of duloxetine on the naloxone induced morphine withdrawal signs in the rats.

\section{Materials and Method}

$\nabla$

\section{Animals}

Male Wistar rats (170-220g) were purchased from the Pasteur Institute in Tehran, Iran. They were housed in the cages in the laboratory temperature $\left(20 \pm 3^{\circ} \mathrm{C}\right)$ and the humidity $(60 \%)$ under a 12-h light-dark cycle. Food (lab chow) and water were available ad labium. 2 days before the experiment, the rats were habit- uated to the testing environment including transfer to the experimental laboratory, weighing, and handling in order to adapt them. All the procedures for the humane treatment of the rats were approved by the Research Committee of the Medical Sciences in Tabriz University. These procedures were performed based on the Guide for Care and Use of Laboratory Animals published by the United States National Institutes of Health (NIH Publication No. 85-23, revised 1985).

\section{Drugs}

The following drugs were used in the present study: morphine sulfate (Temad Company, Iran), naloxane hydrochloride (Daroupakhsah Company, Iran), and duloxetine hydrochloride (Sigma Aldrich, USA).

Morphine sulfate and naloxone hydrochloride were dissolved in $0.9 \%$ physiological saline, and injected subcutaneously and intraperitoneally, respectively. Duloxetine hydrochloride (10, 20 , and $40 \mathrm{mg} / \mathrm{kg}$ ) was dissolved in the sterile water and administered intraperitoneally. Needless to say that the chosen dose of duloxetine was selected based on the previous studies [23-25]. All the solutions were prepared freshly on the experimentation day and exactly before the administration.

\section{Induction of morphine dependence}

Additive doses of morphine were administered subcutaneously for 9 days in order to induce dependence. The procedure of the administration is as follow: day 1: $5 \mathrm{mg} / \mathrm{kg} / 12 \mathrm{~h}$, days 2 and 3: $10 \mathrm{mg} / \mathrm{kg} / 12 \mathrm{~h}$, days 4 and 5: $15 \mathrm{mg} / \mathrm{kg} / 12 \mathrm{~h}$, days 6 and 7: $20 \mathrm{mg} /$ $\mathrm{kg} / 12 \mathrm{~h}$, and days 8 and 9: $25 \mathrm{mg} / \mathrm{kg} / 12 \mathrm{~h}$. On the ninth day, the morning dose of morphine was only injected. This morphine administration protocol showed a high degree production of dependence in the rats [26]. Under the same condition, the rats in non-dependent groups received only saline.

\section{Participants}

Experimental groups

45 male Wistar rats were divided into 5 experimental groups $(n=9)$ randomly. The rats were included in one saline treated group (non-dependent group) and 4 morphine treated groups (morphine-dependent groups). The non-dependent group or saline treated group (group I) was only treated with saline. $30 \mathrm{~min}$ before the morning morphine injection, groups II, III, and IV or in other words the morphine dependent animals received 10,20 , and $40 \mathrm{mg} / \mathrm{kg}$ duloxetine intraperitoneally, respectively. Instead of duloxetine with the same condition, the animals in group $\mathrm{V}$ (the control group) were treated by $0.25 \mathrm{~mL}$ saline intraperitoneally.

\section{Procedures}

Induction of the morphine withdrawal and measurement of the withdrawal behaviors

The experiments of the study were carried out in a quiet room during the light phase of the light-dark cycle. The behaviors of each animal were evaluated by an observer who was not aware of the nature of the treatment received by animals. On the ninth day, $2 \mathrm{~h}$ after the last morphine injection, the rats received naloxone $(4 \mathrm{mg} / \mathrm{kg})$ intraperitoneally in order to induce the withdrawal signs. Subsequently, the rats were placed in a clear plexiglas cylinder test chamber (measuring: $30 \mathrm{~cm}$ diameter and $50 \mathrm{~cm}$ height) that was equipped with a digital camera to record the animal behaviors during $30 \mathrm{~min}$ period following naloxone injection and six distinct behaviors included wet dog shaking, 
Table 1 Weighting factor of different withdrawal signs.

\begin{tabular}{|l|l|}
\hline Behavior signs & Weighting factor \\
\hline Jumping & 4 \\
\hline Wet-dog shake & 5 \\
\hline Abdomen writhing & 5 \\
\hline Genital grooming & 5 \\
\hline Teeth grinding & 10 \\
\hline Rearing & 20 \\
\hline
\end{tabular}

teeth grinding, abdomen writhing, rearing, jumping, and genital grooming were recorded. If necessary, the records were repeated for precise scoring and analysis. The score of each behavior was divided by weighing factor attributed to it ( $\bullet$ Table 1 ), and the results were added and come to a Total Withdrawal Score (TWS) for each animal. The TWS was used as an index of the withdrawal intensity [27-29].

\section{Data analysis}

Statistical comparisons among the experimental groups were made by the one way analysis of variance (ANOVA) followed by Tukey's post hoc test for multiple comparisons. All the results were shown by the mean \pm SEM for 9 rats with the statistical significance set at $\mathrm{p}<0.05$.

\section{Result and Discussion}

As it can be seen in 0 Fig. 1, the administration of naloxone increased the TWS $(39.2 \pm 4.1)$ in the control group (Morphine + Saline) significantly as compared with the saline treated group $(6 \pm 1, p<0.001)$. In addition, 0 Fig. 2 shows that duloxetine administration $(10,20$, and $40 \mathrm{mg} / \mathrm{kg})$ caused a significant reduction in the expression of naloxone-induced TWS when compared with the control group ( $\mathrm{p}<0.01$ for $10 \mathrm{mg} / \mathrm{kg}$, and $\mathrm{p}<0.001$ for $20 \mathrm{mg} / \mathrm{kg}$ and $40 \mathrm{mg} / \mathrm{kg}$ ). Based on $\odot$ Fig. 2, the TWS in the rats that received $20 \mathrm{mg} / \mathrm{kg}$ and $40 \mathrm{mg} / \mathrm{kg}$ duloxetine was significantly $(\mathrm{p}<0.01)$ less than the rats that received $10 \mathrm{mg} / \mathrm{kg}$ duloxetine; it seems that duloxetine reduced the TWS in a dose dependent pattern.

As expected, the administration of naloxone precipitated jumping in the control group $(13.1 \pm 2.3)$, whereas the co-administration of duloxetine $(10,20$, and $40 \mathrm{mg} / \mathrm{kg})$ with morphine decreased the number of jumping $(9.0 \pm 2.1, \mathrm{p}<0.05,4 \pm 1, \mathrm{p}<0.001$, and $3 \pm 1, \mathrm{p}<0.001$, respectively) as compared with the control group ( $\bullet$ Fig. 3). In addition, naloxone-induction of the withdrawal wet dog shake appeared to be greater in the control group than the saline treated animals. In the morphine dependent animals, which received duloxetine $(10,20$, and $40 \mathrm{mg} / \mathrm{kg})$, the naloxoneinduced withdrawal wet dog shakings were attenuated $(14 \pm 4$ ( $p>0.05), 6 \pm 2(p<0.001)$, and $4 \pm 2(p<0.001)$, respectively) in comparison with the control rats ( $\bullet$ Fig. 4). Moreover, the injection of naloxone precipitated a constellation of other withdrawal signs including rearing, teeth grinding, abdominal writhing, and genital grooming. $\triangle$ Table 2 represents the attenuated effects of duloxetine on the incidence of these signs in compression with the morphine dependent group that received only saline.

The results of this study indicated that duloxetine attenuated the severity of the withdrawal signs. Besides, it suggested that the chronic administration of duloxetine, a 5-HT/NE reuptake inhibitor, tempered the naloxone-precipitated withdrawal signs.

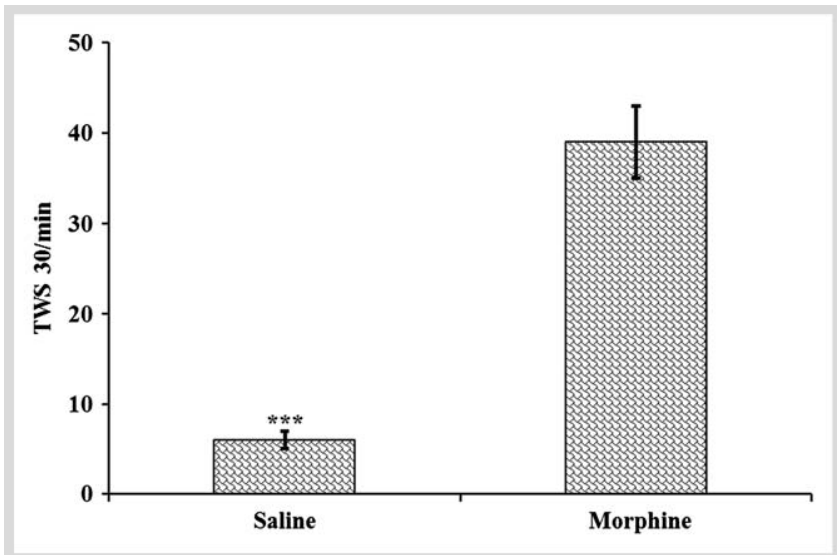

Fig. 1 Naloxone ( $4 \mathrm{mg} / \mathrm{kg}$ )-induced TWS in control group in comparison to saline-saline treated group during $30 \mathrm{~min}$ of experiment. Data are expressed as mean \pm S.E.M. ${ }^{* * *}: p<0.001$ compared to the morphine dependent group; $\mathrm{N}=9$ in each group. TWS: Total withdrawal score.

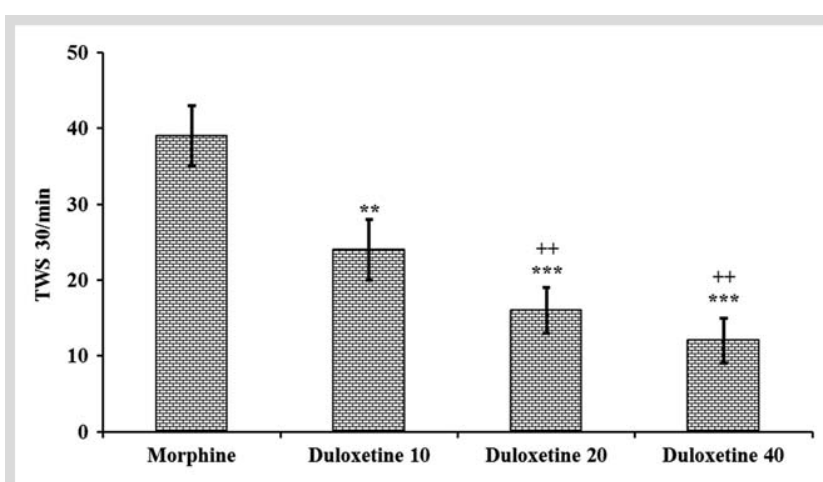

Fig. 2 Effects of intraperitoneal administration of duloxetine (10, 20, $40 \mathrm{mg} / \mathrm{kg}$ ) on the expression of naloxone-induced TWS in morphinedependent rats. Data are expressed as mean \pm S.E.M and were analyzed using a one way ANOVA followed by Tukey's post hoc test. $N=9$ rat in each group. TWS: Total withdrawal score. ${ }^{* *}: \mathrm{p}<0.01$ and ${ }^{* * *}: \mathrm{p}<0.001$ different from morphine-dependent saline treated group. ${ }^{++}: p<0.01$ compared to the morphine dependent rats treated duloxetine $(10 \mathrm{mg} /$ $\mathrm{kg})$.

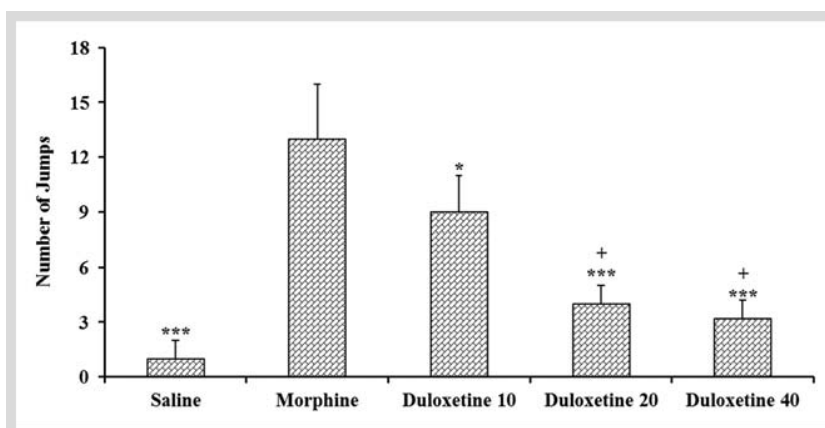

Fig. 3 Effects of intraperitoneal injection of duloxetine on the expression of naloxone-induced jumping in the experimental groups. Data are expressed as mean \pm SEM and were analyzed using a one way ANOVA followed by Tukey's post hoc test. $N=9$ in each group. ${ }^{*}: \mathrm{p}<0.05$ and $*^{* *}: \mathrm{p}<0.001$ compared to the morphine depended group that treated with saline. ${ }^{+}: p<0.05$ compared to the morphine dependent rats treated duloxetine $(10 \mathrm{mg} / \mathrm{kg})$. 
Opiod addiction results from adaptations in specific brain neurons that are caused by the repeated exposure to opiate such as morphine [4]. It is worth noting that the pharmacological treatment of the opioid dependence is limited. Methadone maintenance is the mainstay pharmacotherapy for the opioid dependent patients. In addition, clonidine, central alpha-2 adrenergic receptors agonist, and beta receptors blocker such as propranolol are another therapeutic agents for attenuation of the withdrawal signs $[30,31]$. However, these medicines have their own specific side effects. Thus, many researchers investigated the mechanisms of the withdrawal syndrome to find an effective medical treatment that might improve the ability of addicts to discontinue the opiate intake with less side effects and better quality of efficacy. Hence, alteration in noradrenergic [32], serotonergic [33], dopaminergic [34], purinergic [35], glutamatergic [36], and neurotransmitter systems are reported as possible involvement mechanisms in the morphine withdrawal syndrome. Furthermore, Robert's study suggested that the biogenic amine systems are involved in behavioral and physiological effects of the opiates [37]. Serotonergic and noradrenergic systems are also involved in the physical dependence of the opioid withdrawal $[32,37]$. In this regard, the up-regulation of the cAMP and the increase in the excitatory amino acid (glutamate and aspartate) produce a hyperactivation of the LC during the morphine withdrawal. The synthesis of 5-HT and the NA in brain are regulated by two presynaptic receptors such as $5-\mathrm{HT}_{1 \mathrm{~A}}$ and $\alpha_{2}$ adrenocep-

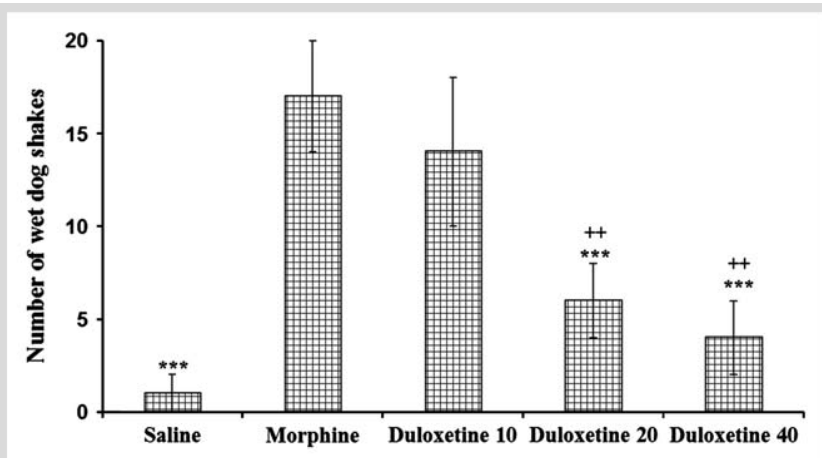

Fig. 4 The number of wet dog shakes in the experimental groups. Data are showed as mean \pm SEM and were analyzed using a one way ANOVA followed by Tukey's post hoc test. $\mathrm{N}=9$ in each group. ${ }^{* * *}: \mathrm{p}<0.001$ compared to the morphine depended group that treated with saline. ${ }^{++}: p<0.01$ compared to the morphine dependent rats treated with duloxetine $(10 \mathrm{mg} / \mathrm{kg})$ tor that regulate those amine syntheses negatively [6]. It has also been reported that the acute morphine administration enhanced the 5-HT turnover as evidenced by an increase in the serotonin synthesis, release, and metabolism [38]. However, a decrease in the release of 5-HT was observed by the chronic morphine administration [39]. In contrast, the acute activation of the $\mu$-opioid receptors decreases the NA synthesis [40]. It is interesting to mention that the synthesis of the NA is increased significantly after the administration of naloxone to the morphine-dependent rats [41], whereas the 5-HT synthesis is decreased after the naloxone-precipitated withdrawal [6]. It is worth noting that increasing the noradrenergic activity of the LC mediates the somatic signs of the opiate withdrawal. In this regard, neuroanatomical studies have indicated that the LC is innervated by the serotonergic fibers and terminals. Glutamate also induces the hyperactivity of the LC that is suppressed by the serotonergic mechanisms $[11,42]$. Besides, Done, et. al. reported that the 5-HT induces the inhibitory effect on the LC hyperactivity that is mediated by the $5-\mathrm{HT}_{2}$ receptors [13]. Moreover, antidepressant drugs with the 5-HT and/or the NA reuptake inhibition activity are frequently used for the treatment of pains related to postherpetic neuralgia, diabetic neuropathy, and fibromyalgia $[43,44]$. Recent studies have also demonstrated that the chronic administration of the antidepressant drug produce an inhibitory effect on the firing rate of the LC. This inhibitory effect has been interpreted as a consequence of the increase in the availability of the NA in the synaptic terminal, and increases the activation of the $\alpha_{2}$ adrenoceptors that exert a tonic inhibitory effect on the firing rate of the LC [45-48].

In the present study, duloxetine, dual 5-HT, and the NA reuptake inhibitor were used in the naloxone induced morphine withdrawal syndrome in rats. The results revealed that the intraperitoneal chronic administration of duloxetine prevented the naloxone precipitated withdrawal signs in the morphinedependent rats in all used concentrations as compared with the control group ( Table 2 and $\odot$ Fig. 2-4). The results of this study also confirm findings of another study that showed the serotonin and the noradrenaline reuptake inhibitor, venlafaxine, attenuated morphine withdrawal signs in the rats [49]. Besides, Rueter, et. al. reported that the chronic administration of duloxetine produced the regulatory effects on both serotonergic and noradrenergic parameters through the desensitization of the somatodendritic 5 - $\mathrm{HT}_{1 \mathrm{~A}}$ autoreceptors and the $\alpha_{2}$-adrenergic hetroceptors [22]. It is possibly hypothesized that the intraperitoneal chronic injection of duloxetine produces the regulatory

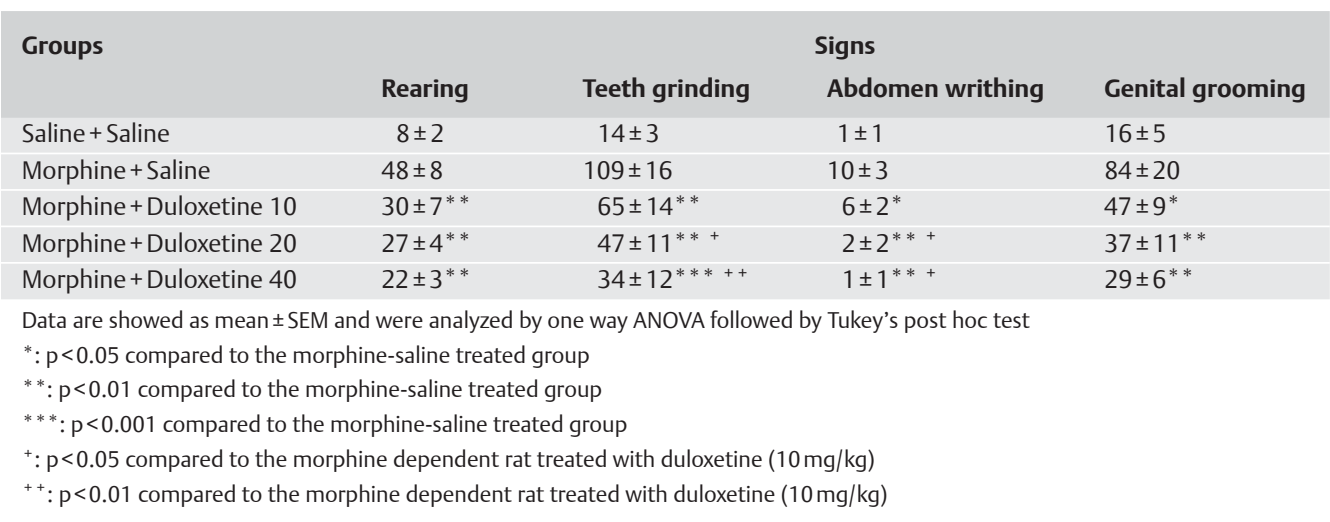

Table 2 A comparison of the frequency of behavioral manifestations by morphine. Withdrawal precipitated by naloxone between the experimental groups during the 30-min observation. 
effects on both serotonergic and noradrenergic parameters, and suppresses the LC hyperactivity during the morphine withdrawal. Moreover, the results of this study indicated that for the first time, duloxetine has a strong potential in the attenuation of the morphine withdrawal, and possibly it is a rational therapeutic choice in the prevention of the opiate dependence and the withdrawal in addicts particularly those suffering from depression. One possible explanation for duloxetine effects on the morphine withdrawal signs is that duloxetine increases the level of the 5-HT at the LC serotonergic nerve terminals through its effects on the 5-HT reuptake, enhances the 5- $\mathrm{HT}_{2}$ receptor activity, and prevents the LC hyperactivity.

\section{Conclusion}

\section{$\nabla$}

The results of this study indicate that duloxetine attenuate naloxone induced withdrawal syndrome in morphine dependent rats. It seems that, chronic intraperitonally injection of duloxetine produces regulatory effects on both serotonergic and noradrenergic parameters, suppresses LC hyperactivity and prevents morphine dependence. Further studies are necessary to determine the exact mechanisms of the observed attenuating effect of duloxetine in morphine withdrawal syndrome.

\section{Acknowledgements}

$\nabla$

We wish to thank the Vice Chancellor's office for Research Affairs of Tabriz University of Medical Sciences for the grant supporting this work. This article is on the base of a Pharm. D thesis (No.3632) results, submitted in the Faculty of Pharmacy, Tabriz University of Medical Sciences, Tabriz, Iran.

\section{Conflict of Interest}

$\nabla$

The authors declare that they had no conflict of interests.

\section{Affiliations}

${ }^{1}$ Department of Pharmacology and Toxicology, Faculty of Pharmacy, Tabriz

University of Medical Sciences, Tabriz, Iran

${ }^{2}$ Biotechnology Research Center, Tabriz University of Medical Sciences, Tabriz, Iran

${ }^{3}$ Student Research Committee, Faculty of Pharmacy, Tabriz University of Medical Sciences, Tabriz, Iran

${ }^{4}$ Research Center for Pharmaceutical Nanotechnology and Department of Pharmaceutics, Faculty of Pharmacy, Tabriz University of Medical Sciences, Tabriz, Iran

${ }^{5}$ Drug Applied Research Center, Faculty of Pharmacy, Tabriz University of Medical Sciences, Tabriz, Iran

\section{References}

1 Riahi E, Mirzaii-Dizgah I, Karimian SM et al. Attenuation of morphine withdrawal signs by a GABAB receptor agonist in the locus coeruleus of rats. Behav Brain Res 2009; 196: 11-14

2 Sadeghi M, Sianati S, Anaraki DK et al. Study of morphine-induced dependence in gonadectomized male and female mice. Pharmacol Biochem Behav 2009; 91: 604-609

3 Childers SR. Opioid receptor-coupled second messenger systems. Life Sci 1991; 48: 1991-2003

4 Nestler EJ, Aghajanian GK. Molecular and cellular basis of addiction. Science 1997; 278: 58-63

5 Gold MS. Opiate addiction and the locus coeruleus. The clinical utility of clonidine, naltrexone, methadone, and buprenorphine. Psychiatr Clin North Am 1993; 16: 61-73
6 Sastre-Coll A, Esteban S, Garcia-Sevilla JA. Supersensitivity of 5-HT1A autoreceptors and alpha2-adrenoceptors regulating monoamine synthesis in the brain of morphine-dependent rats. Naunyn Schmiedebergs Arch Pharmacol 2002; 365: 210-219

7 Maldonado R. Participation of noradrenergic pathways in the expression of opiate withdrawal: biochemical and pharmacological evidence. Neurosci Biobehav Rev 1997; 21: 91-104

8 Maldonado R, Stinus L, Gold L et al. Role of different brain structures in the expression of the physical morphine withdrawal syndrome. J Pharmacol Exp Ther 1992; 261: 669-677

9 Rasmussen K, Beitner-Johnson DB, Krystal JH et al. Opiate withdrawal and the rat locus coeruleus: behavioral, electrophysiological, and biochemical correlates. J Neurosci 1990; 10: 2308-2317

10 Maldonado R, Koob GF. Destruction of the locus coeruleus decreases physical signs of opiate withdrawal. Brain Res 1993; 605: 128-138

11 Pickel VM, Joh TH, Reis DJ. A serotonergic innervation of noradrenergic neurons in nucleus locus coeruleus: demonstration by immunocytochemical localization of the transmitter specific enzymes tyrosine and tryptophan hydroxylase. Brain Res 1977; 131: 197-214

12 Gorea E, Adrien J. Serotonergic regulation of noradrenergic coerulean neurons: electrophysiological evidence for the involvement of 5-HT2 receptors. Eur J Pharmacol 1988; 154: 285-291

13 Done C, Sharp T. Evidence that 5-HT2 receptor activation decreases noradrenaline release in rat hippocampus in vivo. $\mathrm{Br} \mathrm{J}$ Pharmacol 1992; 107: 240-245

14 Hunziker ME, Suehs BT, Bettinger TL et al. Duloxetine hydrochloride: a new dual-acting medication for the treatment of major depressive disorder. Clin Ther 2005; 27: 1126-1143

15 Vaishnavi SN, Nemeroff CB, Plott SJ et al. Milnacipran: a comparative analysis of human monoamine uptake and transporter binding affinity. Biol Psychiatry 2004; 55: 320-322

16 Gould GG, Javors MA, Frazer A. Effect of chronic administration of duloxetine on serotonin and norepinephrine transporter binding sites in rat brain. Biol Psychiatry 2007; 61: 210-215

17 Carter NJ, McCormack PL. Duloxetine: a review of its use in the treatment of generalized anxiety disorder. CNS Drugs 2009; 23: 523-541

18 Detke MJ, Wiltse CG, Mallinckrodt $\mathrm{CH}$ et al. Duloxetine in the acute and long-term treatment of major depressive disorder: a placeboand paroxetine-controlled trial. Eur Neuropsychopharmacol 2004; 14: 457-470

19 Bellingham GA, Peng PW. Duloxetine: a review of its pharmacology and use in chronic pain management. Reg Anesth Pain Med 2010; 35: 294-303

20 Bardin L, Gregoire S, Aliaga $M$ et al. Comparison of milnacipran, duloxetine and pregabalin in the formalin pain test and in a model of stress-induced ultrasonic vocalizations in rats. Neurosci Res 2010; 66: $135-140$

21 Fuller RW, Hemrick-Luecke SK, Snoddy HD. Effects of duloxetine, an antidepressant drug candidate, on concentrations of monoamines and their metabolites in rats and mice. J Pharmacol Exp Ther 1994; 269: 132-136

22 Rueter LE, De Montigny C, Blier P. Electrophysiological characterization of the effect of long-term duloxetine administration on the rat serotonergic and noradrenergic systems. J Pharmacol Exp Ther 1998; 285: 404-412

$23 \mathrm{Ji} C-X$, Fan $D-S, L i W$ et al. Evaluation of the anti-ulcerogenic activity of the antidepressants duloxetine, amitriptyline, fluoxetine and mirtazapine in different models of experimental gastric ulcer in rats. Eur J Pharmacol 2012; 691: 46-51

24 Munro G. Dopamine D1 and D2 receptor agonism enhances antinociception mediated by the serotonin and noradrenaline reuptake inhibitor duloxetine in the rat formalin test. Eur J Pharmacol 2007; 575: $66-74$

25 Grégoire S, Michaud V, Chapuy E et al. Study of emotional and cognitive impairments in mononeuropathic rats: Effect of duloxetine and gabapentin. Pain 2012; 153: 1657-1663

26 Parvizpour A, Charkhpour M, Habibi-Asl B et al. Repeated central administration of selegiline attenuated morphine physical dependence in rat. Pharmacol Rep 2013; 65: 593-599

27 Rasmussen K, Beitner-Johnson DB, Krystal JH et al. Opiate withdrawal and the rat locus coeruleus: behavioral, electrophysiological, and biochemical correlates. The Journal of Neuroscience 1990; 10: 2308-2317

28 Dizgah IM, Karimian SM, Zarrindast MR et al. Attenuation of morphine withdrawal signs by a D1 receptor agonist in the locus coeruleus of rats. Neuroreport 2005; 16: 1683

29 Riahi E, Mirzaii-Dizgah I, Karimian SM et al. Attenuation of morphine withdrawal signs by a GABAB receptor agonist in the locus coeruleus of rats. Behav Brain Res 2009; 196: 11-14 
30 Chen SQ Zhai HF, Cui YY et al. Clonidine attenuates morphine withdrawal and subsequent drug sensitization in rhesus monkeys. Acta Pharmacol Sin 2007; 28: 473-483

31 Robinson MJF, Armson M, Franklin KBJ. The effect of propranolol and midazolam on the reconsolidation of a morphine place preference in chronically treated rats. Frontiers in Behavioral Neuroscience 2011

32 Navarro-Zaragoza J, Nunez C, Ruiz-Medina J et al. CRF(2) mediates the increased noradrenergic activity in the hypothalamic paraventricular nucleus and the negative state of morphine withdrawal in rats. $\mathrm{Br}$ J Pharmacol 2011; 162: 851-862

33 Lelevich SV, Lelevich $V V$, Novokshonov AA. Neurotransmitter mechanisms of morphine withdrawal syndrome. Bull Exp Biol Med 2009; 148: $184-187$

34 Diaz SL, Kemmling AK, Rubio MC et al. Morphine withdrawal syndrome: involvement of the dopaminergic system in prepubertal male and female mice. Pharmacol Biochem Behav 2005; 82: 601-607

35 Zarrindast MR, Naghipour B, Roushan-zamir F et al. Effects of adenosine receptor agents on the expression of morphine withdrawal in mice. Eur J Pharmacol 1999; 369: 17-22

36 Zhu H, Barr GA. The role of AMPA and metabotropic glutamate receptors on morphine withdrawal in infant rats. Int J Dev Neurosci 2004; 22: $379-395$

37 Roberts MHT. 5-Hydroxytryptamine and antinociception. Neuropharmacology 1984; 23: 1529-1536

38 Arends RH, Hayashi TG, Luger TJ et al. Cotreatment with racemic fenfluramine inhibits the development of tolerance to morphine analgesia in rats. J Pharmacol Exp Ther 1998; 286: 585-592

39 Jolas T, Nestler EJ, Aghajanian GK. Chronic morphine increases GABA tone on serotonergic neurons of the dorsal raphe nucleus: association with an up-regulation of the cyclic AMP pathway. Neuroscience 2000; 95: 433-443
40 Schoffelmeer ANM, Putters J, Mulder AH. Activation of presynaptic $\alpha 2$-adrenoceptors attenuates the inhibitory effect of $\mu$-opioid receptor agonists on noradrenaline release from brain slices. NaunynSchmiedeberg's Arch Pharmacol 1986; 333: 377-380

41 Silverstone $P H$, Done C, Sharp T. In vivo monoamine release during naloxone-precipitated morphine withdrawal. Neuroreport 1993; 4: 1043-1045

42 Aston-Jones G, Akaoka H, Charlety P et al. Serotonin selectively attenuates glutamate-evoked activation of noradrenergic locus coeruleus neurons. J Neurosci 1991; 11: 760-769

43 McCleane G. Antidepressants as analgesics. CNS Drugs 2008; 22: 139-156

44 Hill L, Schug SA. Recent advances in the pharmaceutical management of pain. Expert Review of Clinical Pharmacology 2009; 2: 543-557

45 Grant MM, Weiss JM. Effects of chronic antidepressant drug administration and electroconvulsive shock on locus coeruleus electrophysiologic activity. Biol Psychiatry 2001; 49: 117-129

46 Grandoso L, Pineda J, Ugedo L. Comparative study of the effects of desipramine and reboxetine on locus coeruleus neurons in rat brain slices. Neuropharmacology 2004; 46: 815-823

47 Lacroix $D$, Blier $P$, Curet $O$ et al. Effects of long-term desipramine administration on noradrenergic neurotransmission: electrophysiological studies in the rat brain. J Pharmacol Exp Ther 1991; 257: 1081-1090

48 Mateo Y, Fernandez-Pastor B, Meana JJ. Acute and chronic effects of desipramine and clorgyline on alpha(2)-adrenoceptors regulating noradrenergic transmission in the rat brain: a dual-probe microdialysis study. Br J Pharmacol 2001; 133: 1362-1370

$49 \mathrm{Lu} \mathrm{L,} \mathrm{Su} \mathrm{WJ,} \mathrm{Yue} W$ et al. Attenuation of morphine dependence and withdrawal in rats by venlafaxine, a serotonin and noradrenaline reuptake inhibitor. Life Sci 2001; 69: 37-46 